\title{
Reverse osmosis application in the recycling of zinc from the electroplating shop wastewater
}

\author{
Tadeusz Porębski, Sławomir Tomzik, Włodzimierz Ratajczak, Marzena Talma-Piwowar, \\ Adam Koprowski
}

Industrial Chemistry Research Institute, ul. Rydygiera 8, 01-793 Warsaw, Poland, e-mail: Tadeusz.Porebski@ichp.pl

\begin{abstract}
The paper reveals the results of the research on the reverse osmosis recovery of zinc from galvanic electroplating. The pilot plant tests were performed in an electroplating shop. Raw washings were concentrated with a spiral wound $2.5 \times 40$ " module with a composite polymeric membrane.

The research tests have proved that the proposed RO process enables successful concentration of the nonferrous metal in raw washings. The retentate of the RO process has contained about $96 \%$ of the metal previously wasted in washings discharged to the environment. The retentate can be recycled to the mother electroplating process. The permeate of the RO process can be recycled to the washing system of the electroplating shop.
\end{abstract}

Keywords: galvanic wastewater, zinc recovery, membrane process, reverse osmosis.

Presented at VII Conference Wasteless Technologies and Waste Management in Chemical Industry and Agriculture, Międzyzdroje, 12 - 15 June, 2007.

\section{INTRODUCTION}

After joining the European Union, Poland is obliged to conform its legislation regarding industrial discards to the UE law. The new law imposes maximal reduction of negative effects of industry upon the environment ${ }^{1}$. The goal can be achieved by the development and commercialisation of modest non-wastes processes as well as of the processes of the utilization of wastes. It is worth mentioning that modern processes focus on the recycling of waste material, thereby reducing the consumption of raw material and the bulk of by-products.

Utilization of non-ferrous metals containing wastes is a problem that various branches of industry have in common. It is particularly crucial for the waste water produced in electroplating shops. Galvanic electroplating processes yield various streams of waste water that contain considerable volumes of non-ferrous metals. The wastes are often discharged and pollute the environment.

\section{MEMBRANE PROCESSES IN ELECTROPLATING SHOPS}

The present situation can be improved by a suitable application of energy-saving membrane processes like the reverse osmosis (RO). The RO processes enable a recovery of valuable metals from the treated wastewater and their recycling to the electroplating process ${ }^{2}$.

Zinc, chromium, nickel and copper can be found in an electroplating shop solutions in a considerable concentration, mainly in the electroplating baths, as well as in washings produced when removing electrolyte from the treated elements surface. As long as the electroplating baths are concerned, a membrane process can be applied for the so-called electroplating bath conservation. When the electroplating bath is used for a longer time, some impurities accumulate in it, and their presence adversely affects the quality of the generated electroplating coatings. E.g. in the case of divalent metal salts electrolyte, there are monovalent salts that cause the impurities. They can be removed from the electrolyte solution on nanofiltration membranes that are capable of separating the divalent cations from the monovalent ones.

The concentration of non-ferrous metals in electroplating washings is much lower than in the electroplating baths. Hence they should be concentrated to reduce the volume of the solution being recycled to the electroplating bath. This can be done by distillation, ion exchange or with an application of membrane techniques ${ }^{3}$. A typical distillation is energy-consuming while the application of ion exchangers requires frequent regeneration of the ion exchanger bed, hence the volume of the wastewater produced, is considerable. It seems that membrane techniques lack the above drawbacks and are worth a serious consideration.

Figure 1 shows the idea of recycling of the non-ferrous metals from electroplating washings with membrane techniques ${ }^{4,5}$. Raw electroplating washings from the system of final washers are led to the nanofiltration system or to the reverse osmosis system. They are split there to the permeat stream and to the retentate stream. The permeat stream makes a stream of the treated water. It contains only slight amounts of the metals being recovered and can be recycled to the washing system of the electroplating shop. The retentate stream contains non-ferrous metals being recovered. It can be recycled to the electrolyte tank or to the system of making the electrolyte bath up.

\section{EXPERIMENTAL}

The membranes selected in the laboratory experiments as well as the test procedure were verified in a pilot test in an electroplating shop. There were two stages of the pilot test:

- Pre-treatment (prefiltration) of the treated washing solutions in a sequence of $\mathrm{pH}$ regulation, aeration, filtering ferrous solids off and final thorough filtration;

- Concentration of the recovered metals by membrane filtration of the pre-treated washing solutions. The block diagram of the pilot plant is given in Figure 2. 


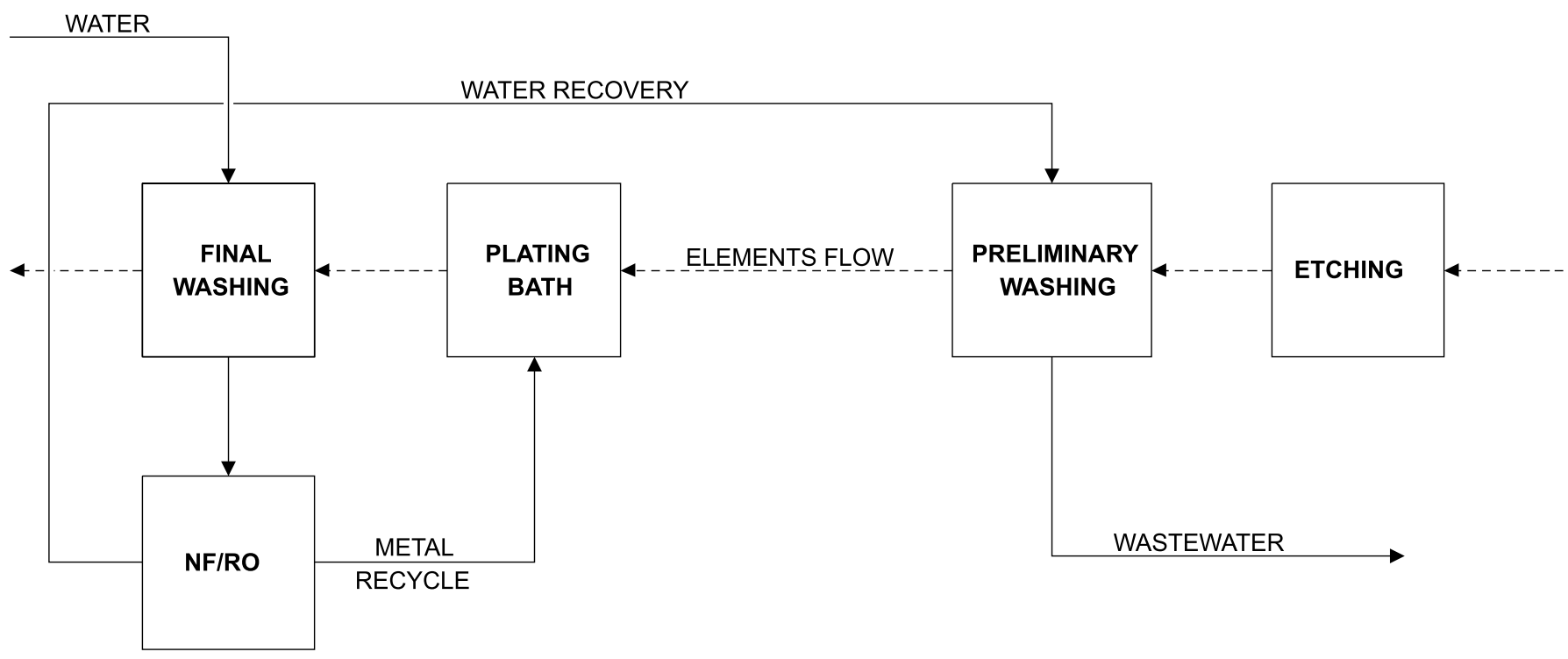

Figure 1. Recovery of zinc from washing solutions

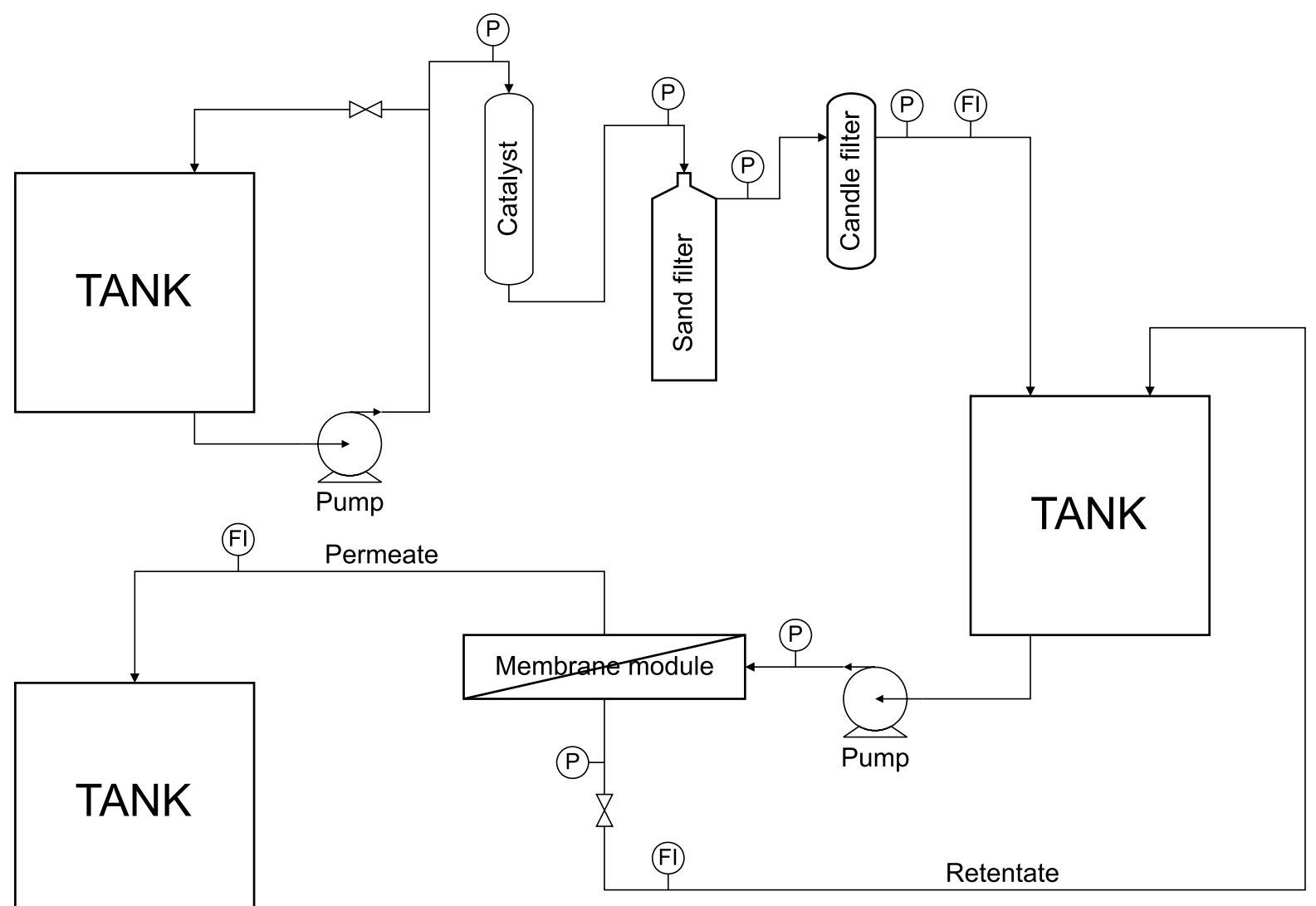

Figure 2. A block diagram of the galvanic washings treatment pilot plant

The pre-filtration set was composed of a Pyrolox catalyst iron remover, $1-2 \mathrm{~mm}$ sand graveller and a protective candle filter with a polypropylene cartridge of $5 \mu \mathrm{m}$ nominal rating. The pre-filtration set was operated at 0.3 - 0.5 MPa, the membrane set (reverse osmosis) was operated at the pressure up to $5.5 \mathrm{MPa}$ at the constant temperature of $303{ }^{\circ} \mathrm{K}$. The reverse osmosis process was run in a batch manner i.e. with the retentate recycling to the feed tank. A spiral wound 2.5"x40" module with a polyamide composite TFC-SW KOCH membrane $\left(2.3 \mathrm{~m}^{2}\right.$ area) of $\mathrm{NaCl}$ retention of about $99.5 \%$ was used in the test. The pre-filtration system and the reverse osmosis system were fed with high-pressure CAT piston pumps.
The research was performed on washing solutions produced in the course of washing of the elements plated in galvanic zinc coating in acid chloride bath. The treated solutions were taken directly from the electroplating shop bath. The content of the raw washing is given in Table 1 below.

Analytical control of the test was performed by the measurement of the electrolytic conductivity and of the $\mathrm{pH}$ changes with Elmetron CX-742 Meter, the turbidity was measured by Hach $2100 \mathrm{~N}$ IS Turbidity Indicator, and SDI index was determined with Millipore SDI Tester. The process parameters of pressure, temperature and flow were measured with suitable meters located on pipes and in tanks. 
Table 1. The characteristics of raw electroplating washings concentrated by the reverse osmosis

\begin{tabular}{|l|l|r|}
\hline \multirow{4}{*}{ Average content, $\mathrm{mg} / \mathrm{dm}^{3}$} & Calcium & 100.0 \\
\cline { 2 - 3 } & Potassium & 3500.0 \\
\cline { 2 - 3 } & Iron & 2.0 \\
\cline { 2 - 3 } & Zinc & 1200.0 \\
\cline { 2 - 3 } & Chlorides & 4000.0 \\
\hline Conductivity, $\mathrm{mS}$ & \multicolumn{2}{|c|}{14.0} \\
\hline Turbidity, NTU & \multicolumn{2}{|c|}{15.0} \\
\hline $\mathrm{pH}$ & \multicolumn{2}{|c|}{7.5} \\
\hline
\end{tabular}

\section{RESULTS AND DISCUSSION}

The pre-treatment stage yielded in the reduction of turbidity of the treated solution from about 5 NTU to as little as 0.3 NTU. The iron content was reduced from about 2 $\mathrm{mg} / \mathrm{dm}^{3}$ to below $0.01 \mathrm{mg} / \mathrm{dm}^{3}$. The SDI index (Silt Density Index) for the pre-treated solution was below 2 .

The reverse osmosis process split the feedstock stream to the concentrated retentate (up to $30 \%$ of the feedstock stream) and the permeat stream (the balance volume). The exemplary results of the pilot tests (two charges) are given on diagrams below. Figure 3 shows the changes in the tested membrane module permeability and Figure 4 shows the changes in the electrolytic conductivity of the permeates and the retentates. All the above changes are vs. the permeate volume.

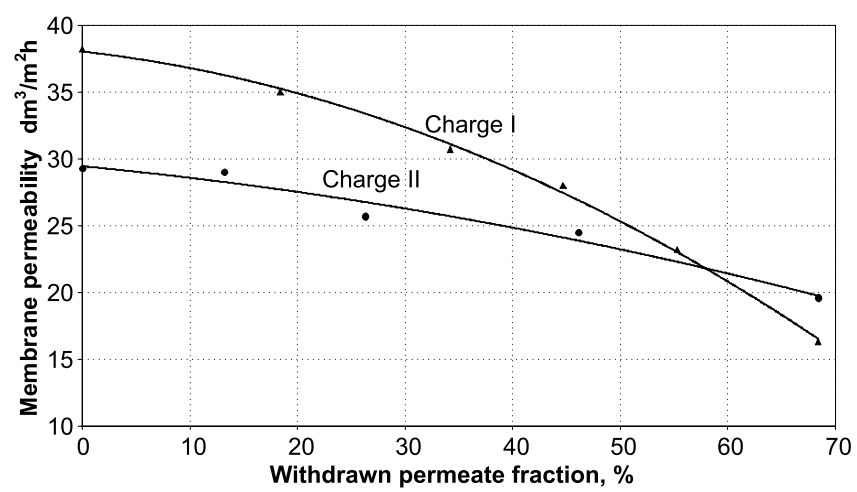

Figure 3. Changes in the tested membrane module permeability

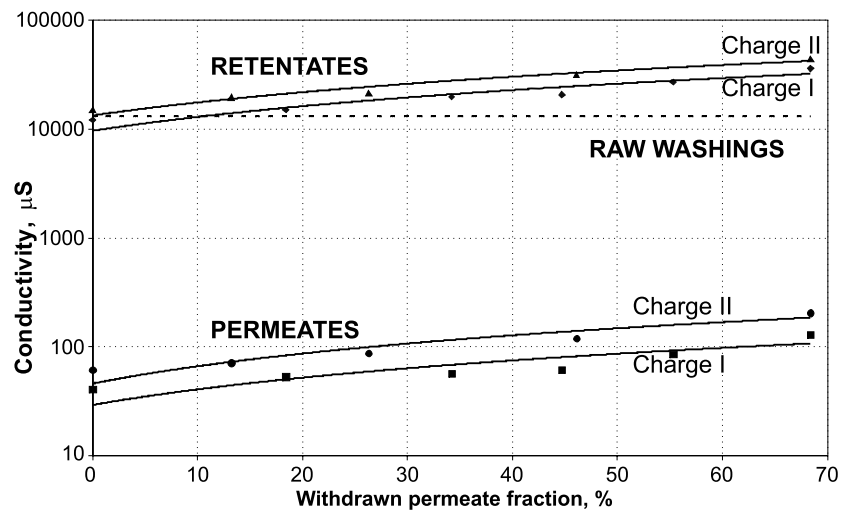

Figure 4. Changes in the electrolytic conductivity of the permeates and the retentates

In the course of the pilot tests both the permeability of the membrane and the quality of the permeate produced have decreased. As the process was run in a batch manner i.e. the retentate was constantly recycled to the feed tank, in the recycle stock the concentration of the compounds halted by the membrane, increased. That is why the conductivity of the recycled stock increased from $14 \mathrm{mS}$ for raw washings to about $35 \mathrm{mS}$ for the final retentate. The reverse osmosis process was run at constant trans-membrane pressure. The increase of salt concentration in the recycled stock resulted in the increase of the osmotic pressure of the treated solution. Therefore, the driving force of the reverse osmosis process decreased and so did the permeate flux of the membrane. The permeate flux decrease was enhanced by the membrane fouling ${ }^{6}$ i.e. by a layer of contaminants that was formed on the membrane surface. This can be very clearly seen in Charge I when the tested module was brand-new. In the tests described in the paper, some $1.2 \mathrm{~m}^{3} / \mathrm{h}$ of washings was passed through the membrane module. The diagram 4 shows the initial permeate flux of Charge II was lower than that for Charge I, and it can be noticed that in Charge II the permeate flux decrease in relation to the whole test is lower, too. This can prove the successful formation of hydrodynamic conditions inside the module that restrained the formation and the growth of the surface layer on the membrane surface. The difference in the initial value of the permeate flux for the two charges may result both from the possible interaction of membrane and its surface layer and from greater salinity of the washings treated in Charge II.

After withdrawing $65 \%$ of the raw feedstock in the form of the permeate stream, the permeability of the membrane has decreased to $20 \mathrm{dm}^{3} / \mathrm{m}^{2} \mathrm{~h}$ i.e. to $50 \%$ of its initial value. In the course of withdrawing of the permeate, the raw washing solutions in the feed tank are being concentrated. In the final stage of the test the conductivity of the permeate was about $120 \mu \mathrm{S}$ and that means that the retention of salts was still very high $-99.7 \%$.

Table 2 shows the results (Charges I and II) of the measurements for the final streams gained in the reverse osmosis separation of electroplating washings. The final retentate has made $35 \%$ of the raw washing solutions feed and the concentration of zinc in the retentate was three times the value for the raw feed and it was as high as $4000 \mathrm{mg} / \mathrm{dm}^{3}$. The average permeate stream zinc content was about $1.0-$ $2.5 \mathrm{ppm}$ and the chlorides content was $15 \mathrm{mg} / \mathrm{dm}^{3}$.

\section{CONCLUSION}

The pilot tests revealed the proposed process capability of successful treating of washing solutions from washing of the elements plated in galvanic zinc coating in acid chloride bath. The efficiency and the capacity of the process depend on the quality of the treated waste water. For the washing solutions treated in the pilot tests the final retentate streams contained $92-96 \%$ of the raw washing solutions zinc content. The final retentate makes the full value raw material for the electroplating bath, hence it can be successfully recycled for the mother process. The research showed that the final effect can be achieved with the proviso that the membrane process is preceded by multistage pre-filtration of the treated waste water.

\section{ACKNOWLEDGEMENTS}

The authors of the paper wish to express their gratitude to the staff of ANKOR, Łódź for their assistance in the pilot plant tests. 
Table 2. The results of the measurements for the final streams gained in the reverse osmosis separation of electroplating washings

\begin{tabular}{|c|c|c|c|c|c|c|}
\hline \multirow[b]{2}{*}{ Component } & \multirow[b]{2}{*}{ Unit } & \multirow[b]{2}{*}{ Raw waste water } & \multicolumn{2}{|c|}{ I Charge } & \multicolumn{2}{|c|}{ II Charge } \\
\hline & & & Permeate & Retentate & Permeate & Retentate \\
\hline $\mathrm{Zn}^{2+}$ & $\mathrm{mg} / \mathrm{dm}^{3}$ & 1100 & 1 & 3400 & 3 & 4100 \\
\hline $\mathrm{K}^{+}$ & $\mathrm{mg} / \mathrm{dm}^{3}$ & 2700 & 12 & 9050 & 11 & 11150 \\
\hline $\mathrm{Cl}^{-}$ & $\mathrm{mg} / \mathrm{dm}^{3}$ & 3760 & 13 & 12160 & 15 & 15080 \\
\hline Conductivity & $\mathrm{mS}$ & 14 & 0.1 & 36 & 0.1 & 44 \\
\hline
\end{tabular}

\section{LITERATURE CITED}

(1) Directive 2006/12/EC of the European Parliament and of the Council of 05.04.2006 on waste.

(2) Schoeman J.J., Steyn A., Scurr P.: Treatment using reverse osmosis of an effluent from stainless steel manufacture, Water Research, 1996, 30 (9), 1979 - 1984.

(3) Steward F.A., McLay W.J., Reinhard F.P.: Waste minimization and recovery technologies, Metal Finishing, 1999, 97 (1), 823 - 824, 826, 828, 830, 832, 834, 836.

(4) Bodzek M., Bohdziewicz J., Konieczny K.: Techniki membranowe w ochronie środowiska, Wydawnictwo Politechniki Śląskiej, Gliwice, 1997, 308 - 310, in Polish.

(5) Anielak A.M.: Chemiczne i fizykochemiczne oczyszczanie ścieków, PWN, Warszawa, 2000, 246, in Polish.

(6) Rautenbach R.: Procesy membranowe, WNT, Warszawa, 1996, 163 - 166, in Polish. 